\title{
Malignant Triton Tumor
}

National Cancer Institute

\section{Source}

National Cancer Institute. Malignant Triton Tumor. NCI Thesaurus. Code C4335.

A malignant peripheral nerve sheath tumor which shows rhabdomyosarcomatous

differentiation. More than half of the patients have neurofibromatosis type 1. The prognosis is usually poor. 